\title{
Changes in Climate, Forest Phenology, and Forest Disturbances Around Western Lake Superior
}

\author{
Matthew Garcia 1,2,3 \\ Edgar R. Canavan (P.I.) $)^{2}$ \\ Department of Forest \& Wildlife Ecology \\ University of Wisconsin-Madison \\ Madison, Wisconsin, USA
}

\begin{abstract}
This work proceeds from two hypotheses. First, we can explain much of the observed seasonal and year-to-year variability in forest phenology using weather and climate observations. Seasonal forest phenology is driven by the progress of the warm season: it is observed that frost events can stop spring growth and that seasonal droughts can degrade forest health. What we don't quite know yet is how strong the roles of climate change and weather variability are in these processes. Second, linking anomalies in observed phenology (by remote sensing methods) with climatological analyses can indicate the occurrence, extent, and possible causes of forest disturbances. We pursue two primary interests here: (1) observations of regional climatology and its variability in the area around western Lake Superior, and (2) identifying the influence of climate variability on forest phenology and disturbances in that area.
\end{abstract}

\section{Introduction and Background}

Forests have a particularly important role at the land surface: Earth's surface energy budget, water cycle, carbon cycle, and numerous nutrient cycles all intersect in forest areas. Forest vigor and growth interact both directly and indirectly with changes in climate [Pope et al., 2013; Marchin et al., 2015], complicating our ability to predict forest phenology, estimate carbon sequestration, and represent clearly the numerous land-atmosphere interactions within the climate system [Peñuelas et al., 2009; Richardson et al., 2013]. Proximity to large water bodies, such as Lake Superior, can affect local and regional temperature and precipitation patterns [Changnon and Jones, 1972; Scott and Huff, 1996; Hinkel and Nelson, 2012]. Spatiotemporal warming patterns and consequential changes in forest phenology will vary considerably in the Great Lakes region [Reyer et al., 2013].

\footnotetext{
${ }^{1}$ Advised by Prof. Philip Townsend, Department of Forest \& Wildlife Ecology, University of Wisconsin-Madison. ${ }^{2}$ The author's 2015-2016 Wisconsin Space Grant Consortium (WSGC) Graduate Research Fellowship is gratefully acknowledged. Additional support was provided by the USDA Forest Service-Northern Research Station, USDA NIFA McIntire-Stennis funding to the University of Wisconsin-Madison (project WIS01621), UW-Madison College of Agricultural and Life Sciences, UW-Madison Department of Forest \& Wildlife Ecology, NASA Biodiversity and Ecological Forecasting Project NNX14AC36G, and the UW-Madison Center for High Throughput Computing (CHTC) in the Department of Computer Sciences.
}

${ }^{3}$ Portions of this work are currently in review for publication in the Journal of Geophysical Research-Atmospheres. 
Meteorological and climatological factors have been shown to significantly influence vegetation seasonal phenology [Jolly et al., 2005; Koster et al., 2014; Xie et al., 2015] and explain a large fraction of observed year-to-year variability in temperate forest phenology [Fisher et al., 2007; Marchin et al., 2015], specifically as a primary factor in the annual growing season start, intensity, and duration. Changes may promote altered trajectories of forest health (e.g. due to moisture stress and other disturbance factors) and species composition, favoring more drought-resistant species in some areas and more shade-tolerant species in others [Duveneck et al., 2014]. Trophic interactions between forest vegetation, insects, and wildlife become more uncertain with altered timing of phenological events [Foster et al., 2013; Roberts et al., 2015]. Forest managers with responsibility for planning winter and dry-season harvest territories, or for undertaking intervention activities to mitigate forest disturbances due to insect pests and fire, may benefit from any potential improvements in seasonal predictability.

In the first part of this work we have focused on describing changes in basic and derived climate indicators, from seasonal and annual temperature and precipitation measures to a novel definition of the climatological growing season. We have assessed long-term climatological means, trends, and interannual variability in large forested areas around the western end of Lake Superior during 1984-2013, coincident with a 30-year collection of Landsat observations over the same region. Changes in the climatology and related weather patterns of the Great Lakes region [Sousounis and Grover, 2002; Hayhoe et al., 2010; d'Orgeville et al., 2014] are expected to affect both vegetation phenology [Jolly et al., 2005; Schwartz et al., 2006; Groffman et al., 2012; Gunderson et al., 2012; Richardson et al., 2013] and forest disturbance regimes [Hufkens et al., 2012; Filewood and Thomas, 2014]. We are working to demonstrate these effects by detailed association of meteorological and climatological observations with multispectral remote sensing observations of forest areas, from which we can derive measures of forest cover, its progression through the growing season (phenology), and changes to that progression over successive years that may indicate a forest disturbance event.

The second, ongoing part of this work addresses observations of forest phenology using Landsat images over the 1984-2013 period and diagnosis of the associations between phenology and its climatological influences. Vegetation phenology refers here to the seasonal timing of events in a tree's annual physiological cycle, including leaf budburst and growth, senescence, and (for deciduous species) abscission. Phenology also includes flowering and seed production, the generation of annual growth rings in stemwood, winter hardening and spring sap flush, and other less visible processes. The timing of phenological events is both driven and constrained by environmental conditions: photosynthesis balances carbon assimilation with moisture loss and nutrient transport, and the tree must protect itself against temperature-related stresses such as freezing during spring and autumn transitions [Kim et al., 2014] and moisture-related stresses in hot and/or dry periods [Anderegg et al., 2012]. The pace of photosynthesis is itself sensitive to environmental conditions, especially temperature [Ali et al., 2015], and varies over time with leaf phenological phases and tree growth stage. 


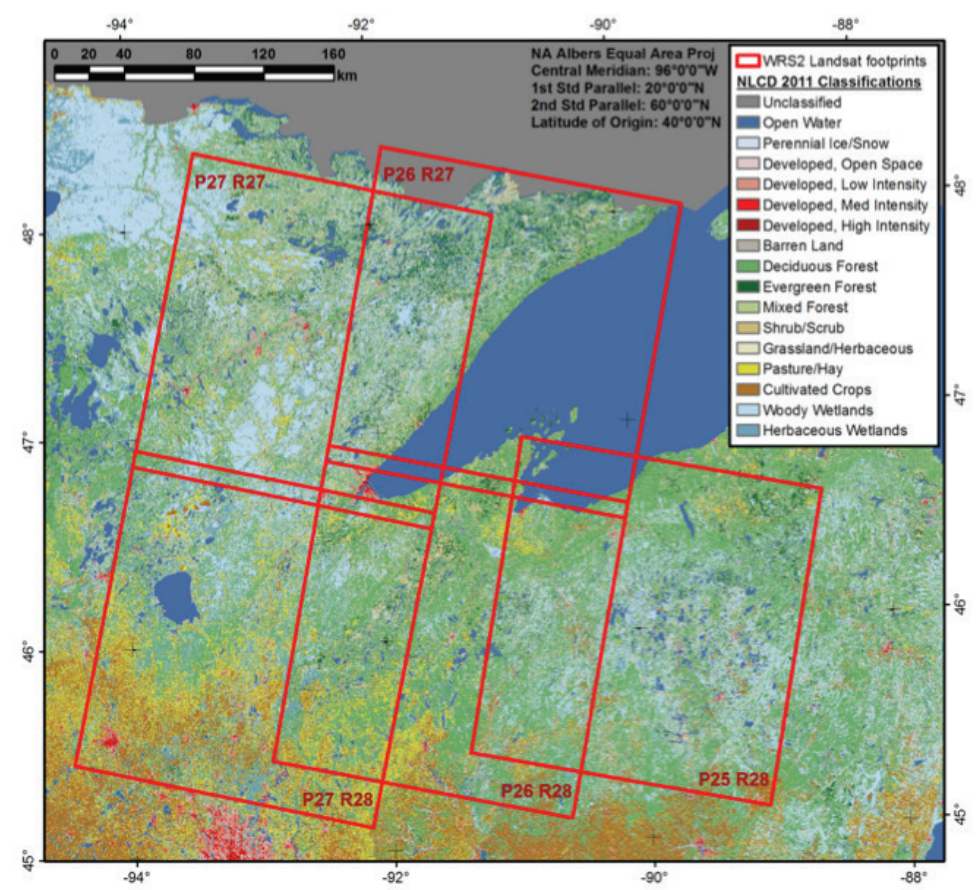

Fig. 1: Study area extent with NLCD land cover classifications and Landsat footprints.

\section{Study Area, Data, and Methods}

Our study area covers $\sim 202,000 \mathrm{~km}^{2}$ of sub-boreal evergreen and midlatitude mixed forest around the western end of Lake Superior in the North American Upper Great Lakes (Fig. 1). Our choice of study area reflects a particular challenge arising from a complex combination of regional wwinfluences. A "tension zone" [Curtis and McIntosh, 1951] that traverses our study area is defined by a combination of geographic transitions, from warm and dry continental interior to cool and wet lake-influenced landscapes. This ecotone marks gradients in both soil types and natural vegetation types [Danz et al., 2013; Bockheim and Schlieman, 2014], from prairie and hardwood forests in the southwest (now mixed with agriculture) to sub-boreal evergreen and temperate mixed forests closer to Lake Superior. This region is sensitive to changing forest ecology and management practices, recreational use, logging pressure, regional warming and climate change, and the recent accelerated warming of Lake Superior [Austin and Colman, 2007, 2008; Van Cleave et al., 2014]. Upper Great Lakes forests are increasingly vulnerable to disturbance factors and tree mortality as a consequence of seasonal moisture stress and fire risk [Irland et al., 2001].

We developed climatological statistics using daily precipitation $(\mathrm{P})$ and minimum and maximum temperature $(T)$ observations from the GHCND dataset [Durre et al., 2010; Menne et al., 2012] for more than 400 unique locations in and near our study area during 1983-2013. This dataset, instructions for obtaining datasets for other locations, and the Python code used in our analysis are available from the author. We cleaned this dataset using available quality assurance flags and then used valid station data to generate daily gridded temperature and precipitation fields at 480-m spatial resolution by radial basis functions [Akkala et al., 2010]. We calculated several seasonal statistics such as the mean and variance of $\mathrm{T}$ and $\mathrm{P}$ over 90 -day and 365 -day periods. In total we 
evaluated 40 climatological indicators, including several that have been used to assess changing climate extremes by Frich et al. [2002] and Alexander et al. [2006].

With this dataset we also calculated accumulated chilling days (CD) and growing degree days (GDD) [Baskerville and Emin, 1969; Thompson and Moncrieff, 1982] on a daily basis using a base temperature of $5^{\circ} \mathrm{C}$ following several empirical studies of tree physiology and spring phenology [Cannell and Smith, 1983; Murray et al., 1989; Hunter and Lechowicz, 1992; Fisher et al., 2007; Viherä-Aarnio et al., 2014]. We then defined the vegetation growing season in two ways. The first is a traditional definition based on the last spring frost and first autumn frost dates $\left(\mathrm{T}_{\min }<0^{\circ} \mathrm{C}\right)$ [e.g. McCabe et al., 2015]. Frost dates and the duration of the frost-free season are useful for assessing long-term seasonal changes as well as acute indicators of potential for vegetation freeze damage, especially in the transition from cold to warm seasons. We also defined the growing season as a function of chilling day (CD) accumulation, which reaches a warm-season plateau as GDD accumulation begins in the spring and departs from that plateau in autumn as GDD accumulation ceases. These conceptual definitions are illustrated below. Our plateau-based growing season is several days longer than the frost-free season for the same year. In cases where a late spring frost can damage new foliage, or an early autumn frost might hasten leaf senescence, the differences between these season starting and ending dates are of great interest to us.

We obtained remote sensing images for the ongoing portion of our work from the USGS. We selected 200-250 Landsat images for each of the five footprints shown in Fig. 1, all with relatively low cloud cover (typically $<50 \%$ ) and occurring between March and October to catch the growing season. We processed these images from at-satellite radiance measurements to top-of-atmosphere reflectance values, and then to surface reflectance, using the LEDAPS software package [Masek et al., 2008]. We applied the object-based Fmask software package [Zhu and Woodcock, 2012] to identify and remove clouds and their shadows from each image. We also derived a water mask in order to eliminate rivers and lakes from the images using both USGS NLCD datasets [Homer et al., 2015] and a water-oriented threshold derived from the images themselves. We derived an image mask containing areas classified as forest (of any type) at any time in our study period in order to restrict our analysis of phenological processes and potential disturbance events to our areas of interest, excluding agriculture and urban areas from that focus. Finally, vegetation "greenness" as an indicator of phenological stage is often represented by a number of different spectral indices derived from processed Landsat surface reflectance images. We have elected to focus on several traditional indices (e.g. NDVI) and a number of other, potentially underutilized indices such as NDII and the Tasseled Cap transformation [Jin and Sader, 2005]. Our ongoing work with these analyses is described below.

\section{Climatological Analysis Results}

Area-averaged 1984-2013 mean daily temperature observations for our study area are shown in Fig. 2, which also provides a conceptual overview of key temperature-related climate variables that we analyze including CD, FD and GDD accumulation, mean last spring and first autumn frost dates, and mean CD plateau beginning and ending dates. We found an area-average trend of $+0.56^{\circ} \mathrm{C}$ in annual mean temperatures during $1984-2013$, with spring cooling (net $-1.26^{\circ} \mathrm{C}$ ) offset by warming in all other seasons, especially autumn (net $\left.+1.54^{\circ} \mathrm{C}\right)$. Cooler 


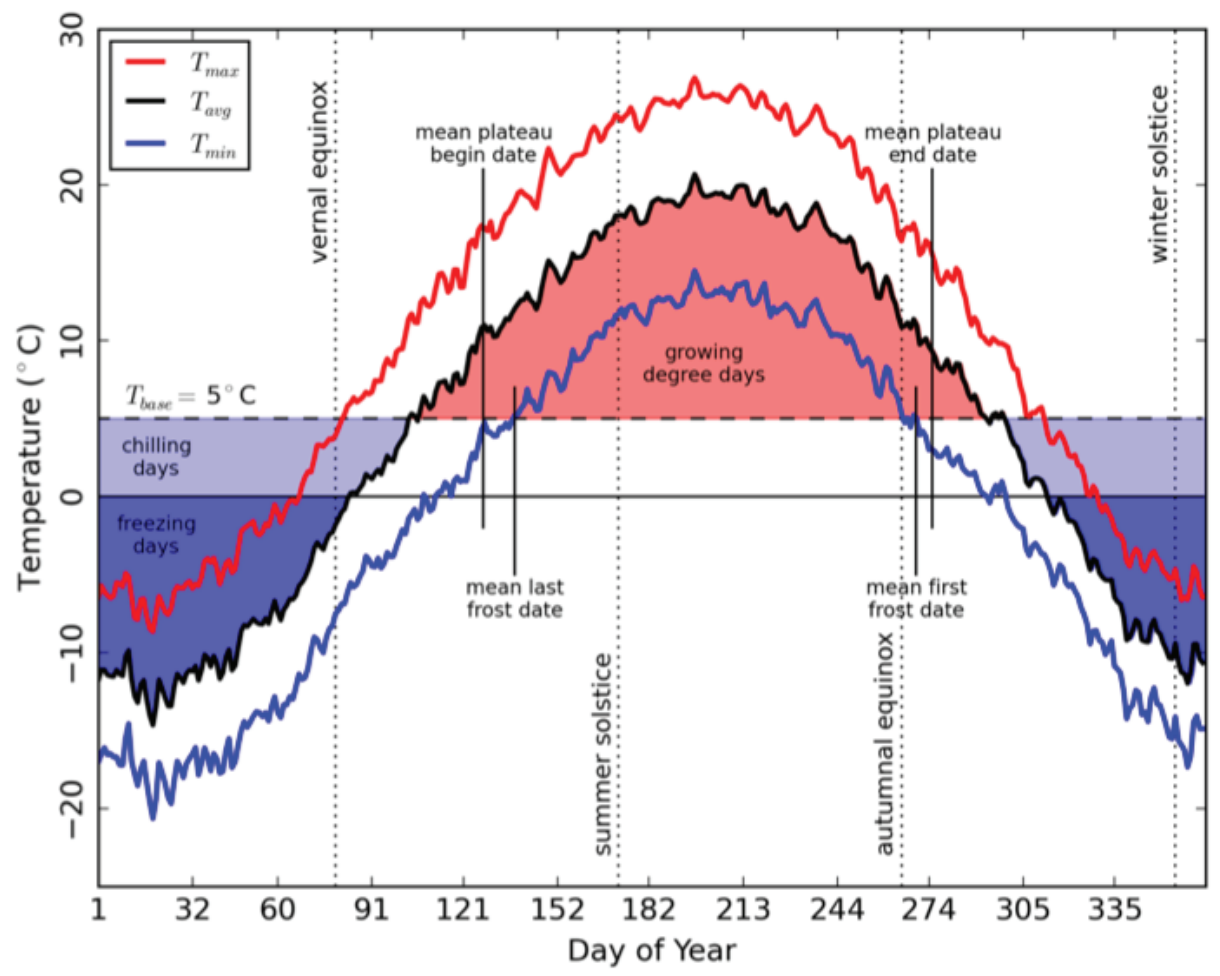

Fig 2: Area-averaged 1984-2013 mean daily temperature, with seasonal indicators marked.

temperatures in spring and summer are generally concentrated on the Minnesota shore of Lake Superior, and the coolest temperatures in all seasons occur in the land areas northwest of the lake. Warmer temperatures in autumn and winter are generally concentrated on the Wisconsin/ Michigan (southern) shore of Lake Superior, although some warm locations are also found along the Minnesota (northern) shore. Summer precipitation showed an area-wide temporal trend of $-0.34 \mathrm{~cm} / \mathrm{y}(p<0.01)$, despite changes of the opposite sign in some portions of our study area, but overall consistent with a trend in summer precipitation days $(\mathrm{P}>0)$ of -0.25 days $/ \mathrm{y}(p<0.001)$.

During autumn and winter the areas of greatest precipitation are concentrated on the southeast side of the lake where prevailing northwesterly winds carry lake-evaporated moisture onshore. Conversely, precipitation totals appear suppressed downwind of Lake Superior in the spring and summer, consistent with prior observations [Changnon and Jones, 1972]. Lake Superior plays an important role in seasonal temperature and precipitation patterns on adjacent land areas. Later ice formation in autumn and winter allows an extended period of surface evaporation and enhanced lake-effect precipitation, whereas cold-season ice cover from mid-winter through early spring typically inhibits lake evaporation and precipitation in downwind regions.

Area-mean annual accumulations of CD and GDD (Figs. 3a and 3b, respectively) illustrate the CD plateau during the growing season. The duration of the frost-free season, our traditional measure of the climatological growing season, shows an area-average trend of +0.32 days $/ y(p<0.05)$ over our study period that is consistent with previous findings [Kunkel et al., 2004; Yu et al., 2014; McCabe et al., 2015]. The end of the CD plateau, our alternative measure to indicate the end of the growing season, showed an area-wide trend of +0.27 days $/ y(p<0.05)$ over the 30-year 
study period that is consistent with autumn warming. Over the study area we found a trend in the accumulation of GDD before the last spring freezing night of -2.1 days/y $(p<0.05)$, suggesting a diminishing risk of vegetation-damaging late frost events over our study period.

(a)

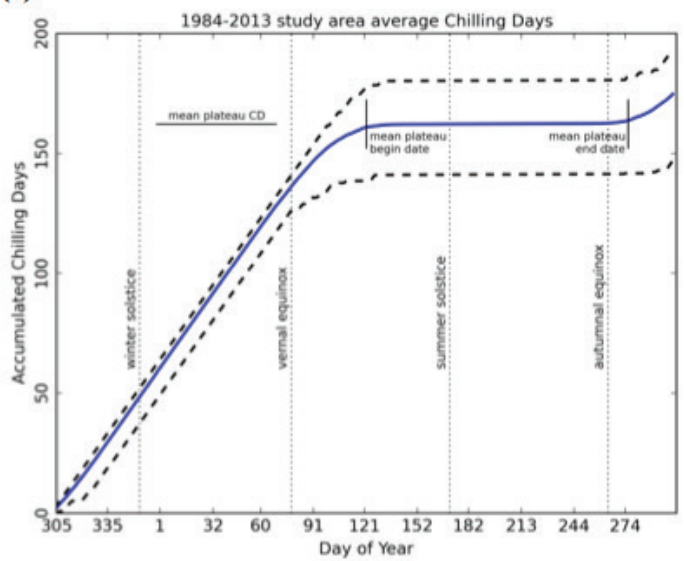

(b)

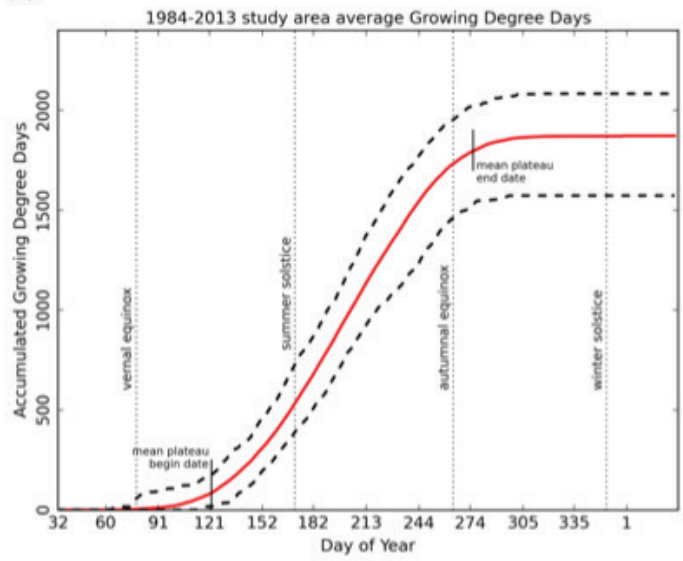

Fig 3: Area-averaged 1984-2013 mean CD (a) and GDD (b) accumulations, with seasonal indicators marked.

\section{Discussion}

Our estimated $+0.56^{\circ} \mathrm{C}$ area-average temperature change is consistent with prior estimates of warming in this region over similar periods [Li et al., 2010; Groisman et al., 2012]. Our results show a consistent continuation of trends reported for 1951-1980 climatic changes in the Great Lakes region reported by Scott and Huff [1996]: increased minimum temperatures in all seasons, decreased spring and summer maximum temperatures, slight decreases in summer rainfall, and large winter precipitation increases for lake-effect areas primarily southeast of Lake Superior and as winter ice cover diminished. Using both traditional and new definitions of the growing season, we have identified an overall extension of the climatological growing season into autumn. Our new definition, based on a warm season plateau in CD accumulation, provides additional information for diagnosing early-season freezing risks and later periods of potential vegetation moisture stress, both of which can have a strong influence on seasonal and interannual variability in vegetation phenology. Some risks such as late spring frost [Hufkens et al., 2012] and "false spring" events [Augspurger, 2009] remain location-specific, and are not characterized well with area-averaged metrics. Though the beginning of the CD plateau in spring has changed little, we have noted the extension of the $\mathrm{CD}$ plateau later into autumn consistent with long-term temperature increases in that season. Overall these results point to a longer climatological growing season in a manner consistent with findings by Jeong et al. [2011].

With area-wide warming and drying, forests in our study area may experience increasing moisture stress during the growing season. It is important to distinguish between changes affecting moisture availability, based primarily on precipitation, and those that drive vegetation moisture demand, based primarily on temperature. Vegetation stress can occur when soil moisture availability is insufficient to meet transpiration demand. Conditions promoting moisture stress can inhibit transpiration and reduce growth [Teskey et al., 1987], promote leaf wilt and early senescence 
[Munné-Bosch and Alegre, 2004; Marchin et al., 2010], enhance tree mortality [Anderegg et al., 2012, 2013], and reduce carbon uptake over long times [Brzostek et al., 2014; Koster et al., 2014].

(a)

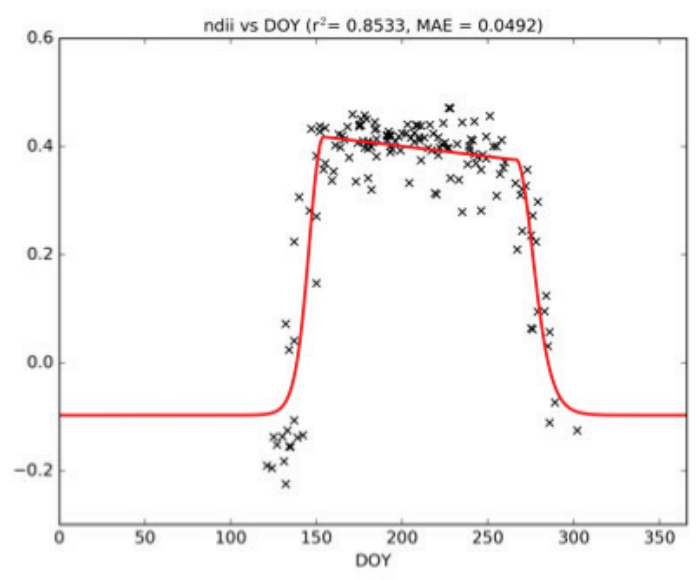

(b)

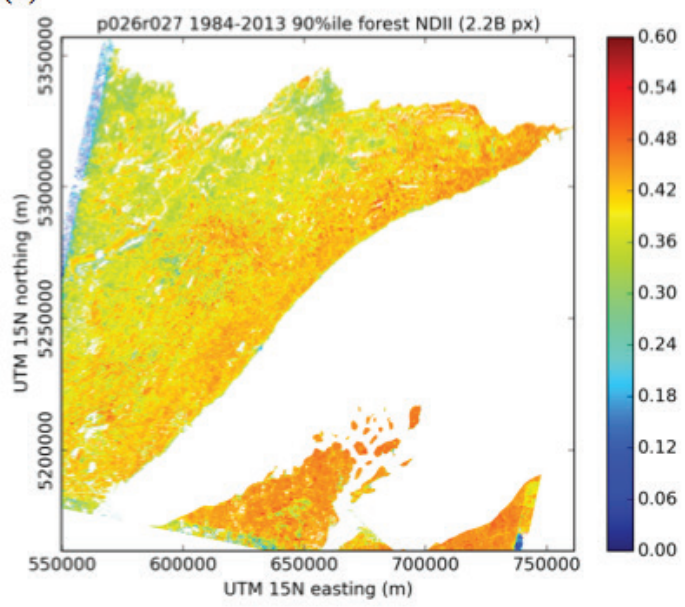

Fig. 4: Individual location analysis of phenology using NDII (a) and resulting map of peak potential NDII (b).

\section{Ongoing Phenological Analysis}

Our climatological work described above supports our exploratory, observational effort to understand long-term changes in vegetation phenology, including seasonal environmental cues and the impacts of climatological variability on forest phenology, disturbances, and postdisturbance forest recovery. We can measure phenology with a number of parameters, such as Landsat vegetation indices (Fig. 4a). We are often most interested in the timing and rate of greenup, the peak greenness, and the timing and rate of senescence. One possible product is shown in Fig. 4b, where we have developed a map of expected peak NDII for the Landsat footprint in Fig. 1 that includes the Superior Forest. The NDII is generally more sensitive to vegetation moisture content than NDVI [Isaacson et al., 2012], allowing us to detect changes such as vegetation drying over time and factor that into phenology, forest health, and disturbance likelihood.

Given data quality (primarily due to cloud cover) and availability in the Landsat record, it is rare that enough images are available in a single growing season for us to evaluate all phases of the annual phenological cycle, let alone repeat that process across every growing season in a 30-year period. Using calculations of several vegetation indices from our multi-spectral Landsat images, we have adopted an approach that aggregates these observations over a number of years in order to diagnose the typical phenological cycle in each location (the result illustrated in Fig. 6a). We then cross-reference each Landsat image with our daily maps of weather, climatology, and growing season indicators to determine the expected phenological pattern. Using the entire image series in a Landsat footprint, we can analyze vegetation index values against the chilling days and growing degree days for the same dates and locations to show the progress of forest phenology from spring green-up through autumn senescence. We then calculate deviations from the expected phenological pattern, and relate those to deviations in climatology for the image dates. We anticipate that this spatially-detailed process will show how different climate factors drive variability in the actual 
forest phenology across a range of vegetation types and patterns.

While minor deviations from expected phenological cycles may be related to interannual climate variability, we expect that large deviations likely indicate forest disturbance events. There are a number of ways to map forest disturbances, such as before-and-after image differencing methods. Using our Landsat-based vegetation indices, we can often obtain maps of the disturbance extent and some measure of its severity, but it can be difficult to detect mild disturbances or the effects of such factors as drought and insect attack that can accumulate over long times. The final part of this work will focus on a combination of vegetation indices and climatological analyses to indicate not only the location and severity of possible forest disturbances, but also attribute each event to observable causes. We can use classification methods (e.g. decision trees) applied to our climatological and phenological analyses to describe the causes and severity of forest disturbances, with which we can more accurately track the pace and progress of forest recovery.

References

Akkala, A., V. Devabhaktuni, and A. Kumar, 2010: Interpolation techniques and associated software for environmental data . Environ. Prog. Sust. Energy, 29, 134-141, doi: 10.1002/ep.10455.

Alexander, L.V., and 23 coauthors, 2006: Global observed changes in daily climate extremes of temperature and precipitation. J. Geophys. Res. Atmos., 111, paper no. D05109, doi: 10.1029/2005JD006290.

Ali, A.A., and 11 coauthors, 2015: Global-scale environmental control of plant photosynthetic capacity. Ecol. Appl.,25, 2349-2365, doi: 10.1890/14-2111.1.

Anderegg, W.R.L., J.M. Kane, and L.D.L. Anderegg, 2012: Consequences of widespread tree mortality triggered by drought and temperature stress. Nature Clim. Ch., 3, 30-36, doi: 10.1038/nclimate1635.

Anderegg, W.R.L., L. Plavcová, L.D.L. Anderegg, U.G Hacke, J.A. Berry, and C.B. Field, 2013: Drought's legacy: Multiyear hydraulic deterioration underlies widespread aspen forest die-off and portends increased future risk. Glob. Ch. Biol., 19, 1188-1196.doi: 10.1111/gcb.12100.

Augspurger, C.K., 2009: Spring 2007 warmth and frost: Phenology, damage and refoliation in a temperate deciduous forest. Functional Ecol., 23, 1031-1039, doi: 10.1111/j.1365-2435.2009.01587.x.

Austin, J.A., and S.M. Colman, 2007: Lake Superior summer water temperatures are increasing more rapidly than regional air temperatures: A positive ice-albedo feedback. Geophys. Res. Lett., 34, paper no. L06604, doi: 10.1029/2006GL029021.

Austin, J., and S. Colman, 2008: A century of temperature variability in Lake Superior. Limnol. Oceanogr., 53, 2724- 2730, doi: 10.4319/lo.2008.53.6.2724.

Baskerville, G.L., and P. Emin, 1969: Rapid estimation of heat accumulation from maximum and minimum temperatures. Ecology,50, 514-517, doi: 10.2307/1933912.

Bockheim, J.G., and S.A. Schliemann, 2014: Soil richness and endemism across an environmental transition zone in Wisconsin, USA. Catena, 113, 86-94, doi: 10.1016/j.catena.2013.09.011.

Brzostek, E.R., D. Dragoni, H.P. Schmid, A.F. Rahman, D. Sims, C.A. Wayson, D. Johnson, and R.P. Phillips, 2014: Chronic waterstress reduces tree growth and the carbon sink of deciduous hardwood forests. Glob. Change Biol., 20, 25312539, doi: 10.1111/gcb.12528.

Cannell, M.G.R., and R.I. Smith, 1983: Thermal time, chill days and prediction of budburst in Picea sitchensis. J. Appl. Ecol., 20, 951-963, doi: 10.2307/2403139.

Changnon Jr., S.A., and D.M.A. Jones, 1972: Review of the influences of the Great Lakes on weather. Wat. Resour.Res., 8, 360371, doi: 10.1029/WR008i002p00360.

Curtis, J.T., and R.P. McIntosh, 1951: An upland forest continuum in the prairie-forest border region of Wisconsin. Ecology, 32, 476-496, doi: 10.2307/1931725.

Danz, N.P., L.E. Frelich, P.B. Reich, and G.J. Niemi, 2013: Do vegetation boundaries display smooth or abrupt spatial transitions along environmental gradients? Evidence from the prairie-forest biome boundary of historic Minnesota, USA. J. Veg. Sci., 24,1129-1140, doi: 10.1111/jvs. 12028.

d'Orgeville, M., W.R. Peltier, A.R. Erler, and J. Gula, 2014: Climate change impacts on Great Lakes basin precipitation extremes. J. Geophys. Res. Atmos., 119, 10,799-10,812, doi: 10.1002/2014JD021855.

Durre, I., M.J. Menne, B.E. Gleason, T.G. Houston, and R.S. Vose, 2010: Comprehensive automated quality assurance of daily surface observations. J. Appl. Meteor. Climatol., 49, 1615-1633, doi: 10.1175/2010JAMC2375.1.

Duveneck, M.J., R.M. Scheller, M.A. White, S.D. Handler, and C. Ravenscroft, 2014: Climate change effects on northern Great Lake (USA) forests: A case for preserving diversity. Ecosphere, 5, article no. 23, doi: 10.1890/ES13-00370.1.

Filewood, B. and S.C. Thomas, 2014: Impacts of a spring heat wave on canopy processes in a northern hardwood forest. 
Glob. Change Biol., 20, 360-371, doi: 10.1111/gcb.12354.

Fisher, J.I., A.D. Richardson, and J.F. Mustard, 2007: Phenology model from surface meteorology does not capture satellite-based greenup estimations. Glob. Change Biol., 13, 707-721, doi: 10.1111/j.1365- 2486.2006.01311.x.

Foster, J.R., P.A. Townsend, and D.J. Mladenoff, 2013: Mapping asynchrony between gypsy moth egg-hatch and forest leafout: Putting the phenological window hypothesis in a spatial context. Forest Ecol. Manage., 287, 67-76, doi: 10.1016/j. foreco.2012.09.006.

Frich, P., L.V. Alexander, P. Della-Marta, B. Gleason, M. Haylock, A.M.G. Klein Tank, and T. Peterson, 2002: Observed coherent changes in climatic extremes during the second half of the twentieth century. Climate Res., 19, 193-212, doi: 10.3354/ cr019193.

Groffman, P.M., and 20 coauthors, 2012: Long-term integrated studies show complex and surprising effects of climate change in the northern hardwood forest. BioScience, 62, 1056-1066, doi: 10.1525/bio.2012.62.12.7.

Groisman, P.Y., R.W. Knight, and T.R. Karl, 2012: Changes in intense precipitation over the central United States J. Hydrometeor., 13, 47-66, doi: 10.1175/JHM-D-11-039.1.

Gunderson, C.A., N.T. Edwards, A.V. Walker, K.H. O'Hara, C.M. Campion, and P.J. Hanson, 2012: Forest phenology and a warmer climate - growing season extension in relation to climatic provenance. Glob. Change Biol., 18, 2008-2025, doi: $10.1111 / \mathrm{j} .1365-2486.2011 .02632 . x$.

Hayhoe, K., J. VanDorn, T. Croley II, N. Schlegal, and D. Wuebbles, 2010: Regional climate change projections for Chicago and the US Great Lakes. J. Great Lakes Res., 36 (Suppl. 2), 7-21, doi: 10.1016/j.jglr.2010.03.012.

Hinkel, K.M., and F.E. Nelson, 2012: Spatial and temporal aspects of the lake effect on the southern shore of Lake Superior. Theor. Appl. Climatol., 109, 415-428, doi: 10.1007/s00704-012-0585-2.

Homer, C.G., J.A. Dewitz, L. Yang, S. Jin, P. Danielson, G. Xian, J. Coulston, N.D. Herold, J.D. Wickham, and K. Megown, 2015. Completion of the 2011 National Land Cover Database for the conterminous United States - Representing a decade of land cover change information. Photogram. Eng. Rem. Sens., 81, 345-354.

Hufkens, K., M.A. Friedl, T.F. Keenan, O. Sonnentag, A. Bailey, J. O’Keefe, and A.D. Richardson, 2012: Ecological impacts of a widespread frost event following early spring leaf-out. Glob. Change Biol., 18, 2365-2377, doi: 10.1111/j.13652486.2012.02712.x.

Hunter, A.F., and M.J. Lechowicz, 1992: Predicting the timing of budburst in temperate trees. J. Appl. Ecol., 29, 597- 604, doi: $10.2307 / 2404467$.

Irland, L.C., D. Adams, R. Alig, C.J. Betz, C.-C. Chen, M. Hutchins, B.A. McCarl, K. Skog, and B.L. Sohngen, 2001: Assessing socioeconomic impacts of climate change on US forests, wood-product markets, and forest recreation. BioScience, 51, 753-764, doi: 10.1641/0006-3568(2001)051[0753:asiocc]2.0.co;2.

Isaacson, B.N., S.P. Serbin, and P.A. Townsend, 2012: Detection of relative differences in phenology of forest species using Landsat and MODIS. Landscape Ecol., 27, 529-543, doi:10.1007/s10980-012-9703-x.

Jeong, S.-J., C.-H. Ho, H.-J. Gim, and M.E. Brown, 2011: Phenology shifts at start vs. end of growing season in temperate vegetation over the Northern Hemisphere for the period 1982-2008. Glob. Change Biol., 17, 2385-2399, doi: 10.1111/j.1365-2486.2011.02397.x.

Jin, S., and S.A. Sader, 2005: Comparison of time series tasseled cap wetness and the normalized difference moisture index in detecting forest disturbances. Remote Sensing of Environment, v. 94, pp. 364-372, doi: 10.1016/j.rse.2004.10.012.

Jolly, W.M., R. Nemani, and S.W. Running, 2005: A generalized, bioclimatic index to predict foliar phenology in response to climate. Glob. Change Biol., 11, 619-632, doi: 10.1111/j.1365-2486.2005.00930.x.

Kim, Y., J.S. Kimball, K. Didan, and G.M. Henebry, 2014: Response of vegetation growth and productivity to spring climate indicators in the conterminous United States derived from satellite remote sensing data fusion. Ag. Forest Meteor., 194, 132-143, doi: 10.1016/j.agrformet.2014.04.001.

Koster, R.D., G.K. Walker, G.J. Collatz, and P.E. Thornton, 2014: Hydroclimatic controls on the means and variability of vegetation phenology and carbon uptake. J. Climate, 27, 5632-5652, doi: 10.1175/JCLI-D-13-00477.1.

Kunkel, K.E., D.R. Easterling, K. Hubbard, and K. Redmond, 2004: Temporal variations in frost-free season in the United States: 1895-2000. Geophys. Res. Lett., 31, paper no. L03201, doi: 10.1029/2003GL018624.

Li, X., S. Zhong, X. Bian, W.E. Heilman, Y. Luo, and W. Dong, 2010: Hydroclimate and variability in the Great Lakes region as derived from the North American Regional Reanalysis, J. Geophys. Res. Atmos., 115, paper no. D12104, doi: 10.1029/2009JD012756.

Marchin, R., H. Zeng, and W. Hoffmann, 2010: Drought-deciduous behavior reduces nutrient losses from temperate deciduous trees under severe drought. Oecologia, 163, 845-854, doi: 10.1007/s00442-010-1614-4.

Marchin, R. M., C.F. Salk, W.A. Hoffmann, and R.R. Dunn, 2015: Temperature alone does not explain phenological variation of diverse temperate plants under experimental warming. Glob. Change Biol., 21, 3138-3151, doi: 10.1111/gcb.12919.

Masek, J.G., C.Q. Huang, R. Wolfe, W. Cohen, F. Hall, J. Kutler, and P. Nelson, 2008: North American forest disturbance mapped from a decadal Landsat record. Remote Sensing of Environment, v. 112, pp. 2914-2926, doi: 10.1016/j.rse.2008.02.010.

McCabe, G.J., J.L. Betancourt, and S. Feng, 2015: Variability in the start, end, and length of frost-free periods across the conterminous United States during the past century. Int. J. Climatol., doi: 10.1002/joc.4315.

Menne, M.J., I. Durre, R.S. Vose, B.E. Gleason, and T.G. Houston, 2012: An overview of the Global Historical Climatology Network-Daily database. J. Atmos. Oceanic Technol., 29, 897-910, doi: 10.1175/JTECH-D-11- 00103.1. 
Munné-Bosch, S., and L. Alegre, 2004: Die and let live: Leaf senescence contributes to plant survival under drought stress. Functional Plant Biol., 31, 203-216, doi: 10.1071/FP03236.

Murray, M.B., M.G.R. Cannell, and R.I. Smith, 1989: Date of budburst of fifteen tree species in Britain following climatic warming. J. Appl. Ecol., 26, 693-700, doi: 10.2307/2404093.

Peñuelas, J., T. Rutishauser, and I. Filella, 2009: Phenology feedbacks on climate change. Science, 324, 887-888, doi: $10.1126 /$ science. 1173004 .

Pope, K.S., V. Dose, D. Da Silva, P.H. Brown, C.A. Leslie, and T.M. DeJong, 2013: Detecting nonlinear response of spring phenology to climate change by Bayesian analysis. Glob. Change Biol., 19, 1518-1525, doi: 10.1111/gcb.12130.

Reyer, C.P.O., and 20 coauthors, 2013: A plant's perspective of extremes: Terrestrial plant responses to changing climatic variability. Glob. Change Biol., 19, 75-89, doi: 10.1111/gcb.12023.

Richardson, A.D., T.F. Keenan, M. Migliavacca, Y. Ryu, O. Sonnentag, and M. Toomey, 2013: Climate change, phenology, and phenological control of vegetation feedbacks to the climate system. Ag. Forest Meteor., 169, 156-173, doi: 10.1016/j.agrformet.2012.09.012.

Roberts, A.M.I., C. Tansey, R.J. Smithers, and A.B. Phillimore, 2015: Predicting a change in the order of spring phenology in temperate forests. Glob. Change Biol., 21, 2603-2611, doi: 10.1111/gcb.12896.

Schwartz, M.D., R. Ahas, and A. Aasa, 2006: Onset of spring starting earlier across the Northern Hemisphere Glob. Change Biol., 12, 343-351, doi: 10.1111/j.1365-2486.2005.01097.x.

Scott, R.W., and F.A. Huff, 1996: Impacts of the Great Lakes on regional climate conditions. J. Great Lakes Res., 22, 845-863, doi: 10.1016/S0380-1330(96)71006-7.

Sousounis, P.J., and E.K. Grover, 2002: Potential future weather patterns over the Great Lakes region. J. Great Lakes Res., 28, 496-520, doi: 10.1016/S0380-1330(02)70602-3.

Teskey, R.O., B.C. Bongarten, B.M. Cregg, P.M. Dougherty, and T.C. Hennessey, 1987: Physiology and genetics of tree growth response to moisture and temperature stress: An examination of the characteristics of loblolly pine (Pinus taeda L.). Tree Physiol., 3, 41-61, doi: 10.1093/treephys/3.1.41.

Thompson, A.J., and S.M. Moncrieff, 1982: Prediction of bud burst in Douglas fir by degree-day accumulation. Can. J. Forest Res., 12, 448-452, doi: 10.1139/x82-069.

Van Cleave, K., J.D. Lenters, J. Wang, and E.M. Verhamme, 2014: A regime shift in Lake Superior ice cover, evaporation, and water temperature following the warm El Niño winter of 1997-1998. Limnol. Oceanogr., 59, 1889-1898, doi: $10.4319 / 10.2014 .59 .6 .1889$.

Viherä-Aarnio, A., S. Soutinen, J. Partanen, and R. Häkkinen, 2014: Internal development of vegetative buds of Norway spruce trees in relation to accumulated chilling and forcing temperatures. Tree Physiol., 24, 547- 556, doi: 10.1093/treephys/tpu038.

Xie, Y., K.F. Ahmed, J.M. Allen, A.M. Wilson, and J.A. Silander Jr., 2015: Green-up of deciduous forest communities of northeastern North America in response to climate variation and climate change. Landscape Ecol., 30, 109-123, doi: 10.1007/s10980-014-0099-7.

Yu, L., S. Zhong, X. Bian, W.E. Heilman, and J.A. Andresen, 2014: Temporal and spatial variability of frost-free seasons in the Great Lakes region of the United States. Int. J. Climatol., 34, 3499-3514, doi: 10.1002/joc.3923.

Zhu, Z., and C.E. Woodcock, 2012: Object-based cloud and cloud shadow detection in Landsat imagery. Remote Sensing of Environment, v. 118, pp. 83-94, doi: 10.1016/j.rse.2011.10.028. 